Peer-Reviewed Article

ISSN: 2162-3104 Print/ ISSN: 2166-3750 Online

Volume 5, Issue 4 (2015), pp. 501-511

(C) Journal of International Students

http://jistudents.org/

\title{
Building Vocabulary for Language Learning: Approach for ESL Learners to Study New Vocabulary
}

\author{
Adel M. Alharbi (Doctoral Candidate) \\ University of Memphis (USA)
}

\begin{abstract}
This project investigated Vocabulary Learning Strategies (VLSs) English Language Learners used; and strategies they thought were effective to them in terms of language proficiency. Using an online survey, 121 participants responded to statements regarding their usage of VLSs. Participants have been divided into two groups: (1) learners with low English proficiency level and (2) learners with high English proficiency level to measure the significance between them in response to the VLS questionnaire. The analysis measured five sets of vocabulary knowledge: building synonyms network, learning definition(s) with contexts, pronunciation process, bookmark word search, and remembering strategy for writing. This project determined that the group with high language proficiency agreed more on the items selected than those with low language proficiency.
\end{abstract}

Keywords: Second Language Acquisition, Vocabulary Learning Strategy, Language learning strategies, English Language Learners

There have been a large number of studies in the field of language learning strategies in the last twenty years (e.g. Lan and Oxford, 2003; Macaro, 2001) (Tseng, Dörnyei, \& Schmitt, 2006). For instance, studies done in the 1970s focused on language learning strategies in general (e.g. Rubin, 1987; Skehan, 1989). However, from a vocabulary acquisition perspective, researchers during that time neglected vocabulary learning as its own subfield of learning strategies (Meara, 1980; Schmitt, 1997). Hence, there is no doubt that vocabulary knowledge is a fundamental aspect of language learning and language use (Nation, 1990, 2001). Adolph and Schmitt (2003) have stated that language learners need to master, at least, 3,000 word families to communicate and understand 95 percent of the language communicated by native speakers. As a consequence, to master new words means that language learners have to fully comprehend vocabulary knowledge of each word they encounter. According to Schmitt, (2010) "form-meaning linkage is the most basic vocabulary knowledge possible" (p. 30). To accept this definition means that language learners need to master both spoken and written forms of vocabulary and distinguish its meaning to craft successful meaningful connections socially and mentally. Also in regard to the vocabulary knowledge, Nation and Waring (1997) described that vocabulary knowledge is a 
gradual process. For English Language Learners (ELLs), building vocabulary is a highly demanding process. Laufer (1998), for instance, stated that lexical competence is the main difference between language learners and native speakers of the target language. To this end, this paper sought to examine the strategies/methods that ELLs and/or language learners thought were most effective for their vocabulary learning. Additionally, this paper mainly focuses on the learning process more than the teaching process when vocabulary acquisition is at stake.

\section{Literature Review}

Vocabulary Learning Strategies (VLSs) have been examined from two main strands: (1) from a cognitive psychological view point, and (2) from a Second Language Acquisition (SLA) perspective (Kudo, 1999). The scope of this paper focuses on the latter. The term learning strategy has been defined as any "specific actions taken by the learner to make learning easier, faster, more enjoyable, more self-directed, more effective, and more transferrable to new situation" (Oxford, 1990; p. 8). The research on vocabulary learning and/or acquisition has not received the primary attention until the early 1980s. To most applied linguists, vocabulary learning was known "as a 'neglected aspect of language learning' " as noted by Meara (1980), who criticized and characterized its negligence in SLA research (Meara, 1980; p. 1; Lightbown, \& Spada, 2006, p. 96). Meara (1980) argued that there were no clear theories on vocabulary acquisition until the late 1970s. Researchers of vocabulary learning, such as Nation (1990), Laufer (1986), and Schmitt (1998), have come to agree that more research is needed to investigate in this area, which has been the focus of several SLA researchers for the last three decades.

ELLs acquire different amounts of vocabulary than native speakers. On the one hand, a recent study showed that the volume of vocabulary acquired by native English speakers is 1,000 words annually before college level, which then becomes 2,000 words per year (Peregoy \& Boyle, 2013). On the other hand, for language learners, the studying time for vocabulary acquisition and/or learning must be doubled especially for academic purposes. In addition to that, most recent research and studies on teaching vocabulary have focused on the necessity to expose ELLs to new words through oral and written resources from several contexts within the curriculum (Peregoy \& Boyle, 2013). Accordingly, in order to capture the global and functional meaning of new vocabulary, language learners are highly encouraged to be exposed to the word knowledge explicitly. For instance, Nation (1990) has claimed that language learners need at least 5-16 times the exposure to master new words. Far from curriculum-based instruction in learning vocabulary, language learners spend an estimated hundreds of hours each week studying or communicating by themselves in which they are exposed to a huge amount of vocabulary per day. Like first language acquisition, second language acquisition is maintained gradually by the learning environment that surrounds ELLs and language learners of a particular language. However, ELLs usually develop vocabulary incidentally through conversation as they network socially with English speakers inside school and out (Peregoy \& Boyle, 2013). In doing so, learners must select the right strategy to reach a better understanding of the new texts they read or study. Hence, it becomes important to know how ELLs study vocabulary and which strategies they follow. It is also important to know which of these strategies are more effective. These are the core questions that guided my research to identify vocabulary learning strategy. There are several VLS introduced in language learning studies. For instance, Peregoy and Boyle (2013), have introduced several vocabulary learning strategies, such as Total Physical Response (TPR),

September/October 2015 http://jistudents.org $\quad$ Volume $5 \bullet$ Issue 4


Webtools for learning vocabulary, Read-Alouds, Word Cards, Word Wall Dictionary, and listgroup-label for beginners up to the self-assessment vocabulary strategies to guide teachers and learners to use these strategies. However, these VLS and others may or may not be presented to ELLs at early stages as needed. Also, Schmitt (1997) stated that language learners typically use different vocabulary learning strategies (Schmitt, 2010). Due to the fact that every learner has their own style of learning vocabulary, some strategies appeared to be more of a practical solution to study new words. Certainly, Oxford (1990) and Hedge (2000), for instance, have emphasized that most learners prefer cognitive or mental strategies to learn new words, understand the basic meaning, categorize them, and put them in groups. This research is based on the researcher's own personal experiences as an ELL using a set of thematically related strategies, which are important for ELLs to have in developing and learning more vocabulary.

\section{VLS Background}

VLS has been one of the most interesting topics for researchers in the last two decades $(\mathrm{Gu}$, 2010). Lexical competence requires rigorous activities in order to master vocabulary knowledge and to assist in language usage. Any plan to use a particular strategy for learning another language must be continuous so L2 learners who are at the beginning can build upon their knowledge of vocabulary and language. Learning strategies, on the other hand, focus more attention on how language learners, whether they are first or second learners, utilize their language learning in specific. Moreover, Weinstein and Mayer (1986, p. 315) defined learning strategies as 'the behaviours and thoughts that a learner engages in during learning that are intended to influence the learner's encoding process' (cited in Tseng et al., 2006). Then, Weinstein, Husman, and Dierking, (2000, p. 727) came to redefine learning strategies as 'any thoughts, behaviours, beliefs, or emotions that facilitate the acquisition, understanding, or later transfer of new knowledge and skills'. Conversely, Nation (2001) has suggested that it would be better to ensure the four applications of any strategy that really need high attention from teachers to apply them in learning new vocabulary rather than looking for a clear definition of learning strategy. He suggested that a strategy must inclusively: (1) involve choice, (2) be complex, (3) gain knowledge about the strategy and advantage from training, and (4) expand the effectiveness of learning new vocabulary and vocabulary use (Nation, 2001).

From SLA perspective, the study of VLS has been seen and researched in two facets: (a) of mental activities by L2 learners and (b) of social and interactional forms in which L2 learners practice their ability to study new words (Kudo, 1999). After introducing and shifting the focus from teaching-oriented era to the learners' behavioral strategy to learn the language in late 1970s, several studies on how a learner maintains and controls language learning then cascaded to open the research theories and practices in favor of vocabulary learning strategies. For instance, Rubin(1987), Skehan (1989), and Oxford (1990) are among those who established great works in language learning strategies (Schmitt, 1997). However, one of the most comprehensive publications on the taxonomy of language learning strategy published by Oxford (1990) explored the learning strategy by dividing it into direct and indirect strategies. Oxford classifies the direct or mental strategy into three sub-categories: (1) Cognitive Strategy, (2) Memory Strategy, and (3) Compensation Strategy. In this group, L2 learners demonstrate and exercise mental access to study vocabulary. In the second group; indirect strategy, L2 learners study vocabulary through (a) Meta-Cognitive Strategy, (b) Affective Strategy, and (c) Social Strategy. Others, as Nation (2001), developed taxonomy of vocabulary learning strategies by categorizing learning strategies 
into: Planning, Sources, and Processes. In the first category, L2 learners must plan ahead for their vocabulary learning. After planning for vocabulary learning, L2 learners can explore the sources of the new words, which is how and where to find information about the new words. In the third strategy, process is the stage to establish vocabulary knowledge based on the previous two strategies. Nation explored the vocabulary learning widely by crafting the most theories and questions about this study matter. Also, Schmitt's VLS work (1997) grouped the strategies of learning new words into Determination Strategy, Social Strategy, Memory Strategy, Cognitive Strategy, and Meta-Cognitive Strategy. Some other researchers, such as Gu and Johnson (1996), have developed taxonomy of VLS that is very close to Oxford's 1990 and Schmitt's 1997 (for more details see Gu \& Johnson, 1996). Additionally, a recent study by Angelini, GarcíaCarbonell, and Watts, (2014) tested the telematic simulation and gaming for 31 EFL students and showed a high positive vocabulary acquisition experience. What is more, the perception about the telematic simulation increased the students' motivation to learn English and gain a larger vocabulary through communicative teaching and learning. Finally, this brief history provides a background about the common schemes of VLS in second language learning; hence, this paper aims to present an overview of them. The discussion about the learning strategies to learn new words will be discussed in the results and discussion section of this paper.

\section{Research Method}

A Likert-scale questionnaire (online) has been used to analyze and interpret how sequentially second language learners look up new words following the five steps continuum as follows: Building synonyms network $\rightarrow$ Learning definition(s) with contexts $\rightarrow$ Listening and pronunciation process $\rightarrow$ Remembering strategy for writing $\rightarrow$ Bookmark word search. Hence, the researcher aimed to explore which of the five sets L2 learners use. Adding to the scope of this research, the questionnaire elicited from participants a response to the five sets of strategies mentioned above in order to rearrange their sequence in which learners look up new words. There were 27 items in the questionnaire with 20 items covering the VLS and seven items seeking information related to L1 background, language level, educational level, visiting English speaking countries, and job position. There were five Likert-scale options to choose from, ranging from (1) Strongly Agree to (5) Strongly Disagree. The reliability score Cronbach's Alpha for this project was $(a=.852)(N=121)$ and one case was excluded for incompletion.

\section{Participants}

A total of 120 participants have completed the online survey. The majority of participants in the study were college students learning a second language. Fourteen participants were from the language center at the U.S. regional university in which this study took place. The participants' L1 background included Arabic, Chinese, Croatian, English, German, Hindi, Japanese, Malay, Spanish, Swedish, Urdu, Vietnamese, Persian, Telugu, and Portuguese, respectively. Furthermore, participants have been divided into two groups: learners with high proficiency level and learners with low proficiency level. Their proficiency level was determined by self-identifying selection from the survey options given. 
Table 1: Vocab-Backup Strategy Description

\begin{tabular}{|c|c|c|c|c|}
\hline Categories & Strategy & Sub-strategy & Assist learners to... & LSS* \\
\hline $\begin{array}{l}\text { Cognitive } \\
\text { Strategy }\end{array}$ & $\begin{array}{l}\text { Synonyms } \\
\text { Relations }\end{array}$ & $\begin{array}{l}\text { - Check synonyms first for } \\
\text { new words. } \\
\text { - Use semantic map for each } \\
\text { word. } \\
\text { - Synonyms mean more } \\
\text { words. } \\
\text { - Build up global knowledge } \\
\text { of new words by knowing } \\
\text { synonyms. } \\
\text { - Experience different } \\
\text { contexts of new words. }\end{array}$ & $\begin{array}{l}\text { - Expands vocabulary size } \\
\text { in the brain. } \\
\text { - To learn and remember } \\
\text { easier. } \\
\text { - Develop strong connection } \\
\text { for word relations and } \\
\text { usages. }\end{array}$ & $\mathrm{R}, \mathrm{W}$ \\
\hline $\begin{array}{l}\text { Meta- } \\
\text { cognitive } \\
\text { \& Social } \\
\text { Strategies }\end{array}$ & $\begin{array}{l}\text { Learning } \\
\text { definition/s } \\
\text { with } \\
\text { contexts }\end{array}$ & $\begin{array}{l}\text { - Guess the meaning from } \\
\text { context before knowing the } \\
\text { meaning. } \\
\text { - Check words' context in } \\
\text { dictionaries. } \\
\text { - Apply different contexts of } \\
\text { a word in speaking \& } \\
\text { writing. } \\
\text { - Check the meaning that fits } \\
\text { the new words' context. }\end{array}$ & $\begin{array}{l}\text { - Proper use of the new } \\
\text { words. } \\
\text { - Apply previous knowledge } \\
\text { to guess the meaning. } \\
\text { - Differentiate specific } \\
\text { contexts of new words. }\end{array}$ & $\begin{array}{l}R, W, \\
L, S\end{array}$ \\
\hline $\begin{array}{l}\text { Social } \\
\text { Strategy }\end{array}$ & $\begin{array}{l}\text { Listening \& } \\
\text { Pronunciati } \\
\text { on strategy }\end{array}$ & $\begin{array}{l}\text { - Listening is the best } \\
\text { practice of all (people, } \\
\text { media, etc). } \\
\text { - Syllable is for sound. } \\
\text { - Private Speech has it all. }\end{array}$ & $\begin{array}{l}\text { - Engage in conversations. } \\
\text { - Enhances listening skills. } \\
\text { - Develop confidence in } \\
\text { speaking skill. } \\
\text { - Improve speaking skill. }\end{array}$ & $\mathrm{L}, \mathrm{S}$ \\
\hline $\begin{array}{l}\text { Meta- } \\
\text { cognitive } \\
\text { Strategy; } \\
\text { Dictionary } \\
\text { Strategies }\end{array}$ & $\begin{array}{l}\text { Bookmark } \\
\text { strategy }\end{array}$ & $\begin{array}{l}\text { - Set up a vocabulary } \\
\text { notebook. } \\
\text { - Check new words daily and } \\
\text { weekly. } \\
\text { - Repetition \& retention } \\
\text { practices. } \\
\text { - Deliberate vocabulary } \\
\text { learning. } \\
\text { - Regularly look up new } \\
\text { words in dictionary. }\end{array}$ & $\begin{array}{l}\text { - Remember new words. } \\
\text { - Evoke memory to use new } \\
\text { words in speaking \& } \\
\text { writing. } \\
\text { - Keep vocabulary learning } \\
\text { updated. } \\
\text { - Endorse both speaking \& } \\
\text { writing skills. } \\
\text { - Enhances long-term } \\
\text { memory practices. }\end{array}$ & $\begin{array}{l}\text { R, W, } \\
\text { L, S }\end{array}$ \\
\hline $\begin{array}{l}\text { Memory } \\
\text { Strategy }\end{array}$ & $\begin{array}{l}\text { Rememberi } \\
\text { ng strategy } \\
\text { for writing }\end{array}$ & $\begin{array}{l}\text { - If I write them, I will keep } \\
\text { them in my mind. } \\
\text { - Picture your word } \\
\text { /visualize new words. } \\
\text { - Use them in writing. } \\
\text { - Check syllable for spelling } \\
\text { practices. }\end{array}$ & $\begin{array}{l}\text { - Increase writing } \\
\text { comprehension. } \\
\text { - Increase vocabulary size } \\
\text { by visualizing new words. } \\
\text { - Evoke learning vocabulary } \\
\text { by writing. }\end{array}$ & $\mathrm{W}, \mathrm{R}$ \\
\hline
\end{tabular}

*Language Skills Scale: R-reading, W-writing, L-listening, S-speaking. 


\section{Results}

The results in general yielded significant interconnections between the five strategies, namely: Building synonyms network $\rightarrow$ Learning definition(s) with contexts $\rightarrow$ Listening and pronunciation process $\rightarrow$ Bookmark word search $\rightarrow$ Remembering strategy for writing. The themes of VLS items in the questionnaire were created based on the five VLS strategies established for the purpose of this research. Hence, the argument for this strategy came after a close relation with the study of vocabulary from an ESL perspective as a learner and teacher to apply them into different learning levels during language development. What's more, it's the researcher's intimacy to bring this issue and pay a closer look on how ELLs practice the VLS during language development. The introduction of the five strategies was developed by the author of this project. They represent memory and cognitive strategies, social and meta-cognitive strategies, and dictionary strategies. To understand the segment parts of this paper, an illustration of the five strategies will be discussed later.

\section{Results Based on the Two Groups}

There are two primary scopes of this paper. The first scope looks at the significance between those with high level of English language and those with the low level in responding to the study questionnaire. The second scope rearranges the Vocab-Backup Strategy (VBS) sequence based on the reliability score of the five sets of strategies presented in this paper (see Table 1). This section, details the first scope, and the following section details the second scope. This study reported the result that ELLs with high language proficiency agreed more on the items presented in the survey than those with low language proficiency.

The mean score for the first group is $(M=2.04)$ versus $(M=2.23)$ for the second group (see Table 2 for more details). This means that L2 learners with high language proficiency attempted to use and follow the five-step strategies more when encountering new words. The division of the two groups is presented in Table 2 and the $M$ has been calculated for each group.

\section{Table 2: The Mean Scores for the Two Groups}

\begin{tabular}{lcc}
\hline Name of the group & $M$ & $n$ \\
\hline Learners with low language proficiency & 2.23 & 30 \\
Learners with high language proficiency & 2.04 & 90 \\
\hline
\end{tabular}

\section{Result Discussion for the Five Sets of VBS}

The following subsections will discuss the results of the five strategies and their arrangement based on the reliability score for each step. The VBS five steps continuum is described as follows: Building synonyms network $\rightarrow$ Learning definition(s) with contexts $\rightarrow$ Listening and pronunciation process $\rightarrow$ Bookmark word search $\rightarrow$ Remembering strategy for writing.

\section{Building Synonyms Network/Synonyms Relations}

Surprisingly, before and after data collection, synonyms relations strategies remained as proposed in the first step as preferred by most ELLs and/or L2 learners in general. However, the significant change is how much ELLs look for synonyms at the first stage when they encounter new words. This has been the focus of this paper to see whether ESL students pay attention to 
synonyms or rely on other information, such as definitions, contexts of the word, or part of speech. The purpose here is to explore the global theme of the new words before going into deep information and not losing the word's meaning connections. Therefore, there are four variables in this step and each one assists ELLs learning new words by focusing on synonyms of that particular word. The first variable is to look for synonyms upon first sight of searching or seeking information. The second variable is forming a semantic map for the new words by drawing upon the most known synonyms around the new word. In this variable, the vocabulary knowledge increases in size in the brain by collecting the most related words to match the new one. The third variable is to see if ELLs recheck new words' synonyms to help in understanding its meaning. This process works as an assisted strategy to gain confidence about the word's meaning and knowing the theme better. The fourth is generalizing the importance of synonyms for vocabulary search as preferred method to comprehend the meaning of new words. These variables were selected based on the researcher's belief upon using them as the first stage of exploring new vocabulary. The mean score for all items related to Using Synonyms to search for new words is $M=2.62$. Table 3 shows the mean for each item in this category. Additionally, in order to place the strategies in order, the reliability statistics were analyzed using synonyms' items scored ( $a=.73)$, which has been placed as the highest mark of the five strategies.

Table 3: Statistical Analysis for Using Synonyms Items $(n=120)$

\begin{tabular}{lcc}
\hline Name of the Items & $M$ & $S D$ \\
\hline Rely on synonyms to build word in groups & 2.36 & 1.15 \\
Lookup synonyms first to know meaning of new words & 2.93 & 1.08 \\
Recheck synonyms if new words were not understood & 2.25 & 1.19 \\
Synonyms is more important than meaning alone & 2.96 & 1.06 \\
\hline
\end{tabular}

\section{Meaning vs. Context}

In the continuum of the five sets, learning definition with context was used, but is referred to here as meaning vs. context to emphasize the confusion between them among ELLs. In this strategy, ELLs record the importance of the meaning and/or the context to help them study for new words. In other words, most ELLs look for meaning of new words without considering the context in which the new word appeared.

Table 4: Statistical Analysis for Meaning vs. Context Items $(n=120)$

\begin{tabular}{|c|c|c|}
\hline Name of the Items & $M$ & $S D$ \\
\hline Guess the meaning from the contexts & 1.94 & 1.09 \\
\hline See new word in examples for better learning it & 1.53 & 1.03 \\
\hline Visualize new words & 2.40 & 1.34 \\
\hline Memorize words context to remember its meaning & 2.09 & 1.13 \\
\hline Check new word while reading to know different context of it & 2.54 & 1.05 \\
\hline I distinguish between definitions and contexts of new words & 2.22 & 1.95 \\
\hline
\end{tabular}

Due to some confusion between which context fits the word's particular meaning among ELLs, this strategy process helps determine the context of the new word and connect the right meaning or definition to it. This strategy has six variables in the questionnaire and their mean 
with the details are shown in Table 4. The calculated mean for all the items related to this strategy is $M=2.12$. Moreover, the reliability score for this category is $a=.72$, which remained in the second process as proposed.

\section{Listening and Pronunciation Strategy}

There are four variables for this step to examine the process of practicing the sound system of the new words and learning how to pronounce them. They range from checking new words' syllables, listening to real conversation and media, and using these new words in speaking. The mean score for all the items related to this step is $M=2.27$ (See Table 5 for more details). The reliability score for this set of strategies reached $a=.60$, which is lower than the previous step.

Table 5: Statistical Analysis for Listening and Pronunciation Items $(n=120)$

\begin{tabular}{lcc}
\hline Name of the Items & $M$ & $S D$ \\
\hline Learn pronunciation of new words by checking its syllables & 2.52 & 1.31 \\
Listen to people how they use words in different context & 2.12 & 1.09 \\
Listening to media to learn pronunciation of new words & 2.48 & 1.25 \\
Use new words in speaking and writing to best remember them & 1.97 & 1.08 \\
\hline
\end{tabular}

\section{Bookmark Strategy}

This strategy was placed earlier on the last process of learning new vocabulary. However, after analyzing the data, it has been moved as the fourth strategy with the reliability score of $a=.48$. There are four variables in this strategy and the mean score for all the items is $M=2.17$. This approach aimed to guide ELLs to a better vocabulary retention and repetition practices using vocabulary notebook, rechecking new words, reviewing a vocabulary list, and checking an online dictionary. Bookmark strategy usually assists ELLs and/or L2 learners to remember new words for long-term memory practices and evoke their usage in the current situation for best vocabulary practices. Table 6 shows the $M$ and $S D$ for the items of this strategy.

Table 6: Statistical Analysis for Bookmark Strategy Items $(n=120)$

\begin{tabular}{lcc}
\hline Name of the Items & $M$ & $S D$ \\
\hline Use variety of strategies to keep track of new words & 2.47 & 1.35 \\
Recheck new words for better understanding & 1.85 & 1.01 \\
Prefer to use online dictionaries & 1.78 & 1.10 \\
Use vocabulary list for new words & 2.60 & 1.31 \\
\hline
\end{tabular}

\section{Remembering Strategy for Writing}

Finally, writing strategies take several processes depending on how much focus L2 learners need in order to obtain particular vocabulary, especially for academic purposes. This strategy has three variables and participants have agreed on all the variables. The $M$ score for this strategy is $M=2.29$. Table 7 illustrates the $M$ and $S D$ for Remembering Strategy for Writing for each item. Despite the fact that writing process is a crucial step in language learning in general and particularly in vocabulary learning, it has been placed as the fifth strategy among the five 
based on the reliability score of $a=.40$. However, this does not mean that writing new words is not necessary for language learning. The writing process came as the last frequency in which L2 learners need to master the graphic art of the target language. The three variables checked if ELLs look for specific information in helping them write new words, such as parts of speech, syllables, and use in writing tasks.

Table 7: Statistical Analysis for Remembering Strategy for Writing Items $(n=120)$

\begin{tabular}{lcc} 
Name of the Items & $M$ & $S D$ \\
\hline Check part of speech before meaning & 2.44 & 1.11 \\
Use new words in speaking and writing to best remember them & 1.97 & 1.00 \\
I check syllables of new words to learn its spelling & 2.47 & 1.33 \\
\hline
\end{tabular}

\section{Discussion and Conclusions}

This paper investigates VLS for ELLs and introduced a vocabulary learning strategy named Vocab-Backup Strategy. The participants of this study were mainly undergraduate and graduate students. They have been divided into two groups. Furthermore, the main purpose was to investigate the difference between the two groups of ELLs based on their L2 proficiency level in response to the learning strategy items in the questionnaire. The examination of this paper looked at sets of five strategies proposed by the author. These sets are (1) Building synonyms network, (2) Learning definition(s) with contexts, (3) Listening and pronunciation process, (4) Bookmark word search, and (5) Remembering strategy for writing. It has been concluded that VLS is a sequential process that ELLs need to practice in learning new words. However, based on the analysis of the data gathered, the group with high language proficiency agreed more on the items selected than those with low language proficiency. Also, as proposed in this paper, the five-step strategies remained in the same sequence except for Remembering Strategy for Writing; which has been moved to the last step and Bookmark Word Search has been placed at number four in this category. The rearrangement of the VBS was based on the reliability score for each set of the sub-strategies presented in the questionnaire. The exception scope of this paper was by looking at VLS from the five steps of strategies orderly to gain confidence in vocabulary knowledge from ESL perspective. After conducting this project, it suggests that VLS should explicitly and continuously be introduced to ELLs from the early stages of language learning and during vocabulary learning practices as well. These strategies should be introduced by teachers and facilitators who work with ESL students on a regular basis. Another suggestion is to introduce these strategies to students and allow them to share their own methods of learning new vocabulary with peers. This method could save time for teachers explaining what and how to look up new words. As a self-regulation matter, vocabulary learning must be included in any new lesson or topic to help integrate mental and social development for ELLs during language learning process. Finally, this work attempts to contribute to in-classroom research on how to better acquire vocabulary and expressions, thus the results are mere orientations to carry out further investigations.

\section{Implications}

Due to the complexity and importance of vocabulary for ELLs, a great emphasis on teaching VLS is required to improve their proficiency compared to their counterpart English speakers at 
the same level. Hence, VLS is highly significant to assist ELLs maintain their skills to build intact relationship with vocabulary during language development. It is to be suggested to offer and expose ELLs to different VLSs in order to sustain their self-regulation practices in the classroom.

Also general examples of the taxonomy of VLS have to be introduced to teachers and students to support and develop vocabulary learning strategies awareness in the classroom. This includes open conversations and practices between students and their peers to exchange some experiences and skills among them. Finally, VLS can increase the level of language development if introduced early in the language acquisition process.

\section{REFERENCES}

Adolphs, S., \&Schmitt, N. (2003). Lexical coverage of spoken discourse. Applied Linguistics, 24(4), 425-438.

Angelini, M. L., García-Carbonell \& Watts, F. (2014). Student perceptions on gain in telematic simulation. In Willy C. Kriz (ed), The shift from teaching to learning: Individual, collective and organizational learning through gaming simulation (pp. 176-186). Austria: WB Verlag.

Gu, Y. (2010). Learning Strategies for Vocabulary Development. Reflections on English Language Teaching, 9(2), 105-118.

Gu, Y., \& Johnson, R. K. (1996), Vocabulary learning strategies and language learning outcomes. Language Learning, 46, 643-679. doi: 10.1111/j.1467-1770.1996.tb01355.x

Hedge, T. (2000). Teaching the language system. In Hedge, T., (1st ed.), Teaching and learning in the language classroom (pp. 109-141). Oxford: Oxford University Press.

Kudo, Y. (1999). L2 vocabulary learning strategies. Retrieved from http://www.111.hawaii.edu/nflc/Networks/NW14/

Lan, R., \& Oxford, R. L. (2003). Language learning strategy profiles of elementary school students in Taiwan. IRAL 41, 339-79.

Laufer, B. (1998). The development of passive and active vocabulary: Same or different? Applied Linguistics, 19, 255-271.

Laufer, B. (2009). Second language vocabulary acquisition from language input and from formfocused activities. Language Teaching, 42(03), 341-354.

Lightbown, P. M., \& Spada, N. M. (2006). Learning Language. In Lightbown, P. M., \& Spada, N. M. (3rd ed.), How languages are learned (pp. 96-100). Oxford: OUP.

Macaro, E. (2001). Learning strategies in foreign and second language classrooms. London, UK: Continuum.

Meara, P. (1980). Vocabulary acquisition: A neglected aspect of language learning. Language Teaching, 13(3-4), 221-246.

Nation, I. S. P. (1990) Teaching and learning vocabulary. New York, NY: Newbury House.

Nation, I. S. P. (2001). The goals of Vocabulary Learning. In Long, M. H., \& Richards, J. C. (1st ed.), Learning vocabulary in another language (pp. 6). Cambridge: CUP.

Nation, I. S. P. (2001). Vocabulary learning strategies and guessing from context. Learning vocabulary in another language(pp. 217-262). Cambridge: Cambridge University Press.

Oxford, R. L. (1990). Language learning strategies: what every teacher should know. Boston, MA: Heinle \& Heinle.

Oxford, R. L. (2003). Language learning styles and strategies: Concepts and

September/October 2015 http://jistudents.org $\quad$ Volume $5 \bullet$ Issue 4


relationships. IRAL, 41(4), 271-278.

Peregoy, S. F., \& Boyle, O. (2013). Words and meanings: English learners' vocabulary development (6th ed.), Reading, writing, and learning in ESL: a resource book for teaching K-12 English learners (pp. 224-248). Boston, MA: Pearson.

Rubin, J. (1987). Learner strategies: Theoretical assumptions, research history and typology. In A. Wenden \& J. Rublin (Eds). Learner strategies in language learning (15-30), Hemel Hemstead, England: Prentice Hall.

Schmitt, N. (1997). Vocabulary learning strategies. In N. Schmitt \& M. McCarthy (Eds), Vocabulary: Description, acquisition, and pedagogy (pp. 199-227). Cambridge, UK: CUP.

Schmitt, N. (1998). Tracking the incremental acquisition of second language vocabulary: A longitudinal study. Language Learning 48(2), 281-317.

Schmitt, N. (2010). Key issues in teaching and learning vocabulary. In R., Chacón-Beltrán, C, Abello-Contesse, \& M. Torreblanca-López (Eds.), Insights into Non-native Vocabulary Teaching and Learning. Multilingual Matters.

Schmitt, N. (2010). Key issues in teaching and learning vocabulary. In R. Chacón-Beltrán, C. Abello-Contesse, \& M. Torreblanca-López (Eds.), Insights into non-native vocabulary teaching and learning (pp. 28-40). Bristol, UK: Multilingual Matters.

Skehan, P. (1991). Individual differences in second language learning. Studies in Second Language Acquisition, 13(2), 275-298.

Tseng, W.-T., Dörnyei, Z., \& Schmitt, N. (2006). A new approach to assessing strategic learning: The case of self-regulation in vocabulary acquisition. Applied Linguistics, 27(1), 78102.

Weinstein, C. E., Husman, J., \& Dierking, D. R. (2000). Self-regulation interventions with a focus on learning strategies. In M. Boekaerts, P. R. Pintrich, M. Zeidner (Eds.), Handbook of self-regulation (pp. 727-747). San Diego, CA: Academic Press. doi:10.1016/B978-012109890-2/50051-2.

Acknowledgment - This research would have not been possible without the great assistantship from professor Amer, M. at West Chester University of PA who devoted so much time to guide my project by his theoretical, practical and statistical advices.

\section{AUTHOR}

ADEL M. ALHARBI, ( $\mathrm{PhD}$ candidate at Department of English at University of Memphis), is holding MA in Applied Linguistics. He is interested in Second Language Acquisition studies, Sociocultural Theory, TESOL, ESL teaching, Language studies, Cultures and Intercultural studies as well. He has been teaching ESL and EFL students for over five years in Saudi Arabia and in U.S. as a volunteer. Email: adlism1@hotmail.com 